\title{
Potential therapeutic effect of targeting glycogen synthase kinase $3 \beta$ in esophageal squamous cell carcinoma
}

\author{
Dilireba Bolidong ${ }^{1}$, Takahiro Domoto ${ }^{1}$, Masahiro Uehara ${ }^{1}$, Hemragul Sabit ${ }^{3}$, \\ Tomoyuki Okumura ${ }^{6}$, Yoshio Endo ${ }^{2}$, Mitsutoshi Nakada ${ }^{3}$, Itasu Ninomiya ${ }^{4}$, \\ Tomoharu Miyashita ${ }^{4,7}$, Richard W. Wong ${ }^{5}$ \& Toshinari Minamoto ${ }^{1 凶}$
}

Esophageal squamous cell carcinoma (ESCC) is a common gastrointestinal cancer and is often refractory to current therapies. Development of efficient therapeutic strategies against ESCC presents a major challenge. Glycogen synthase kinase (GSK) $3 \beta$ has emerged as a multipotent therapeutic target in various diseases including cancer. Here we investigated the biology and pathological role of GSK3 $\beta$ in ESCC and explored the therapeutic effects of its inhibition. The expression of GSK3 $\beta$ and tyrosine $(Y) 216$ phosphorylation-dependent activity was higher in human ESCC cell lines and primary tumors than untransformed esophageal squamous TYNEK-3 cells from an ESCC patient and tumor-adjacent normal esophageal mucosa. GSK3 $\beta$-specific inhibitors and small interfering (si) RNA-mediated knockdown of GSK3 $\beta$ attenuated tumor cell survival and proliferation, while inducing apoptosis in ESCC cells and their xenograft tumors in mice. GSK3 $\beta$ inhibition spared TYNEK-3 cells and the vital organs of mice. The therapeutic effect of GSK3 $\beta$ inhibition in tumor cells was associated with G0/G1- and G2/M-phase cell cycle arrest, decreased expression of cyclin D1 and cyclin-dependent kinase (CDK)4 and increased expression of cyclin B1. These results suggest the tumor-promoting role of GSK3 $\beta$ is via cyclin D1/CDK4-mediated cell cycle progression. Consequently, our study provides a biological rationale for GSK3 $\beta$ as a potential therapeutic target in ESCC.

\author{
Abbreviations \\ ABC Avidin-biotin-peroxidase complex \\ CDK Cyclin-dependent kinase \\ CPARP Cleaved PARP \\ DAPI 4',6-Diamidino-2-phenylindole \\ DMSO Dimethyl sulfoxide \\ dUTP 2'-Deoxyuridine-5'-triphosphate \\ EdU 5-Ethynyl-2'-deoxyuridine \\ FACS Fluorescence-activated cell sorting \\ GS Glycogen synthase \\ GSK3 $\beta \quad$ Glycogen synthase kinase-3 $\beta$ \\ IHC Immunohistochemistry \\ PARP Poly [ADP-ribose] polymerase
}

\footnotetext{
${ }^{1}$ Division of Translational and Clinical Oncology, Cancer Research Institute, Kanazawa University, 13-1 Takara-machi, Kanazawa 920-0934, Japan. ${ }^{2}$ Central Research Resource Branch, Cancer Research Institute, Kanazawa University, Kanazawa, Japan. ${ }^{3}$ Department of Neurosurgery, Graduate School of Medical Sciences, Kanazawa University, Kanazawa, Japan. ${ }^{4}$ Department of Gastroenterological Surgery, Graduate School of Medical Sciences, Kanazawa University, Kanazawa, Japan. ${ }^{5}$ WPI Nano Life Science Institute, Kanazawa University, Kanazawa, Japan. ${ }^{6}$ Department of Surgery and Science, Graduate School of Medicine and Pharmaceutical Sciences, University of Toyama, Toyama, Japan. ${ }^{7}$ Department of Surgical Oncology, Kanazawa Medical University Hospital, Ishikawa, Japan. ${ }^{\bowtie}$ email: minamoto@staff.kanazawa-u.ac.jp
} 


$\begin{array}{ll}\text { PBS } & \text { Phosphate buffered saline } \\ \text { pGSK3 } \beta^{\text {s9 }} & \text { GSK3 } \beta \text { phosphorylated in S9 residue } \\ \text { pGSK3 } \beta^{\text {Y216 }} & \text { GSK3 } \beta \text { phosphorylated in Y216 residue } \\ \text { pGS } 641 & \text { GS phosphorylated at S641 residue } \\ \text { PI } & \text { Propidium iodide } \\ \text { S } & \text { Serine } \\ \text { SD }(s) & \text { Standard deviation(s) } \\ \text { siRNA } & \text { Small interfering RNA } \\ \text { TCGA } & \text { The Cancer Genome Atlas } \\ \text { TUNEL } & \text { Terminal deoxynucleotidyl transferase-mediated dUTP nick end labeling } \\ \text { Y } & \text { Tyrosine }\end{array}$

Esophageal cancer is one of the most common causes of cancer-related death worldwide and is thus a major health challenge. Esophageal squamous cell carcinoma (ESCC) accounts for nearly $90 \%$ of all esophageal cancer cases globally and is highly prevalent in East Africa and Asia, including China and Japan ${ }^{1,2}$. Most patients with advanced stage ESCC require intensive treatment including chemotherapy, chemo-radiotherapy, surgery and combinations of these ${ }^{3}$. However, many patients are refractory to such multi-disciplinary treatments, thereby resulting in dismal clinical outcomes ${ }^{4,5}$. During the last two decades, an increasing number of biologically targeted agents against growth factors (e.g., HER2, epidermal growth factor receptor), angiogenic factors (e.g., vascular endothelial growth factors) and molecules involved in the immune checkpoint have been developed. Some have been approved for the treatment of various cancer types, including esophageal cancer ${ }^{6-8}$. However, ESCC patients appear to derive little benefit from these agents ${ }^{9,10}$. There is still insufficient knowledge of the biological basis of ESCC, despite the whole genome studies of ESCC ${ }^{11-13}$. Therefore, identification of new therapeutic targets is of paramount importance to combat refractory $\mathrm{ESCC}^{10}$.

Accumulating studies indicate that esophageal squamous cell carcinogenesis is initiated by a combination of extrinsic/environmental (e.g., alcohol, cigarette smoking) and intrinsic (e.g., acetaldehyde, an intermediate metabolite of alcohol) carcinogenic factors ${ }^{2,4,5}$. These carcinogenic stimuli cause ESCC to develop through a sequential transformation of squamous epithelial cells to squamous dysplasia (mild to severe, or low-grade and high-grade intraepithelial neoplasia), intraepithelial (in situ) SCC, and ultimately progressing to invasive SCC $^{14}$. An early biochemical characteristic in the process of ESCC development is the lack of glycogen associated with cellular neoplastic transformation. This characteristic enables Lugol's iodine-dye endoscopy, which has long been used for screening and diagnosis of $\mathrm{ESCC}^{2,5}$. Loss of cellular glycogen occurs in mild squamous dysplasia (or low-grade intraepithelial neoplasia) and persists till invasive ESCC ${ }^{2}$, suggesting that impaired glycogen synthesis and/or excess glycogenolysis is involved in ESCC development and progression rather than being a consequence of cellular neoplastic transformation. Glycogen synthase (GS) responsible for glycogenesis is the primary substrate of glycogen synthase kinase (GSK) $3 \beta$ and is inactivated by phosphorylation of its serine (S) 641 residue by GSK3 $\beta^{15,16}$. Thus, we hypothesized that GSK3 $\beta$ is aberrantly expressed and/or activated in ESCC.

GSK3 $\beta$ was initially identified as a serine/threonine protein kinase that phosphorylates and inactivates GS. Subsequent studies revealed that GSK3 $\beta$ regulates multiple biological pathways to maintain normal cellular life and homeostasis ${ }^{15,16}$. GSK3 $\beta$ is normally inactive in cells when its S9 residue is phosphorylated. Upon turning from the inactive to active form following phosphorylation of its tyrosine (Y) 216 residue, GSK3 $\beta$ has been shown to participate in various diseases including glucose intolerance, neurodegenerative disorders, and chronic inflammatory and immunological diseases ${ }^{17}$. Despite its functions against some pro-oncogenic pathways in untransformed cells ${ }^{18}$, we have shown that aberrant expression and activity of GSK3 $\beta$ in tumors sustains tumor cell survival and proliferation as well as invasion and therapy resistance in gastrointestinal and pancreatic cancer, glioblastoma and bone and soft tissue sarcomas. We have also previously clarified the pathways underlying the tumor-promoting roles of GSK3 $\beta$, as well as the therapeutic effects of GSK3 $\beta$ inhibition against these cancer types $^{19,20}$. Several other studies together with ours have advocated GSK3 $\beta$ as a potential theranostic target in more than 25 different cancer types ${ }^{19-23}$. These include rare cancer types such as neuroendocrine neoplasms in the gastrointestinal tract and pancreas ${ }^{24,25}$. Building upon this background knowledge, in the present study we investigated the putative pathological roles for GSK3 $\beta$ in ESCC and explored the effects of GSK3 $\beta$ inhibition against this tumor type and the underlying biological mechanisms.

\section{Materials and methods}

Cell lines and ESCC patients. Human ESCC cell lines (TE-1, TE-5, TE-8, TE-9, TE-10 and TE-15) were obtained from the American Type Culture Collection. We previously established human ESCC KES cell line $^{26}$. These cell lines were maintained in RPMI medium (Sigma-Aldrich) supplemented with $10 \%$ fetal bovine serum and $100 \mathrm{U} / \mathrm{mL}$ penicillin-streptomycin at $37{ }^{\circ} \mathrm{C}$ with $5 \% \mathrm{CO}_{2}$. We prepared normal squamous epithelial TYNEK-3 cells from non-neoplastic esophageal squamous mucosa obtained from the surgical specimen of an ESCC patient, as described previously ${ }^{27}$. The cells were maintained in Keratinocyte SFM (Thermo Fisher Scientific).

This study included 46 patients who underwent surgery for ESCC in the Department of Surgical Oncology at Kanazawa University Hospital between 1988 and 2006 and provided informed consent at the time of the initial diagnosis in compliance with guidelines of Kanazawa University and in accordance with Declaration of Helsinki. Surgical specimens were fixed in neutralized $10 \%$ formalin and embedded in paraffin for routine histopathologic examination and immunohistochemical analysis as described below. Histopathologic characteristics and tumor stage at surgery were defined according to WHO Classification of Tumors of the Digestive System ${ }^{14}$ and the 
TNM classification ${ }^{28}$, respectively. The Kanazawa University Medical Ethics Committee and the University of Toyama Institutional Review Board approved the design and protocols including all experiments in this study.

Western blotting. Cellular protein was extracted from cultured cells and fresh xenograft tumor specimens using lysis buffer (CelLytic MT; Sigma-Aldrich) containing a mixture of protease and phosphatase inhibitors (Sigma-Aldrich). A $20 \mu \mathrm{g}$-aliquot of protein extract was analyzed by Western blotting for the proteins of interest ${ }^{29}$. The amount of protein in each sample was monitored by expression of $\beta$-actin. The following primary antibodies were used at the dilutions shown against both GSK3 isoforms (GSK3 $\alpha$ and GSK3 $\beta ; 1: 1,000$; Millipore), GSK3 $\beta$ (1:1,000; BD Biosciences) and GSK3 $\beta$ fractions that are phosphorylated at the serine (S) 9 residue (pGSK3 $\beta^{\mathrm{S9}}$; 1:1,000; Cell Signaling Technology) and the tyrosine (Y) 216 residue (pGSK3 $\beta^{\mathrm{Y} 216} ; 1: 1,000$; BD Biosciences); glycogen synthase (GS; 1:1,000; Cell Signaling Technology) and its fraction phosphorylated at the S641 residue (pGS ${ }^{S 641} ; 1: 1,000$; Cell Signaling Technology); cyclin D1 (1:1,000; MBL); cyclin-dependent kinase (CDK)4 (1:1,000; Abcam), cyclin B1 (1:1,000, Cell Signaling Technology), poly[ADP]-ribose polymerase (PARP; 1:1,000; Cell Signaling Technology), cleaved (c)-PARP (1:1,000; Cell Signaling Technology), and $\beta$-actin (1:4,000; Ambion).

Measurement of intracellular glycogen. Concentration of intracellular glycogen was analysed using Glycogen Colorimetric Assay Kit II (BioVision) and was compared between TYNEK-3 and ESCC cell lines. TE-5, TE- 8 and TE-10 cells were treated for $24 \mathrm{~h}$ with dimethyl sulfoxide (DMSO; Sigma-Aldrich) or with one of the GSK3 $\beta$ inhibitors: AR-A014418 (Calbiochem) ${ }^{30}$ or SB-216763 (Sigma-Aldrich) ${ }^{31}$ at $25 \mu \mathrm{mol} / \mathrm{L}$. Then, intracellular glycogen concentrations were compared between the respective cells treated with DMSO or either of the GSK3 $\beta$ inhibitors.

Immunohistochemical examination. Representative paraffin sections of primary tumors and corresponding adjacent non-neoplastic (at the proximal surgical margin) tissues from ESCC patients were examined for expression and phosphorylation of GSK3 $\beta$ and GS by the avidin-biotin-peroxidase complex (ABC) method as described previously ${ }^{32}$. Tissue sections were deparaffinized and then microwaved for 15 min in Target Retrieval Solution ( $\mathrm{pH}$ 9.0; Dako). Nonspecific immune reaction was blocked by incubation of sections in methanol containing $0.3 \% \mathrm{H}_{2} \mathrm{O}_{2}$ for 30 min followed by incubation in $5 \%$ skim milk (Wako) at room temperature for $1 \mathrm{~h}$. The sections were incubated with either of the mouse antibodies against GSK3 $\beta$ (1:200 dilution) and pGSK3 $\beta^{\mathrm{Y} 216}$ (1:500) (both from BD Biosciences) or of the rabbit antibodies against GS (1:200) and $\mathrm{pGS}^{\mathrm{S} 641}$ (1:200) (both from Cell Signaling Technology) overnight at $4{ }^{\circ} \mathrm{C}$. They were then washed and the corresponding secondary antibody was applied for $30 \mathrm{~min}$. Sections were exposed to diaminobenzidine peroxidase substrate (Funakoshi) for $1 \mathrm{~min}$ and counterstained with Mayer's hematoxylin. Histological and immunohistochemical images were observed and captured using Keyence BZ-X700 Analyzer (Version 1.3, Keyence). For the respective molecules, the mean percentage of immunohistochemistry (IHC)-positive tumor cells in 5 microscopic fields was calculated for each tumor section and classified into five scores as follows: $0,<10 \% ; 1,10 \sim 25 \% ; 2,26 \sim 50 \%$; 3, $51 \sim 75 \%$; and 4,> 76\%. Based on the IHC scores, the expression level of the respective molecules was determined as low (score 0 to 2 ) or high (score 3 and 4 ) according to our previous study ${ }^{32}$.

ESCC databases analysis. Genomic and molecular profiles of ESCC were obtained from The Cancer Genome Atlas (TCGA; https://cancergenome.nih.gov/). According to the previous report ${ }^{33}$, the analysis tool UALCAN (https://ualcan.path.uab.edu/) was used to study levels of GSK3 $\beta$ mRNA expression in normal $(n=11)$ and tumor $(n=184)$ tissues in ESCC patients, and to compare the levels of tumor GSK3 $\beta$ mRNA expression with different clinicopathologic features including age, gender, smoking habits and body weight of patients, and with tumor grades and stages.

Analyses for cell survival, proliferation and apoptosis. Cells seeded in 96-well plates were treated with DMSO or with one of the GSK3 $\beta$ inhibitors: AR-A014418 ${ }^{30}$, SB-216763 31 or LY2090314 (Sigma-Aldrich) ${ }^{34}$ dissolved in DMSO at the indicated final concentration in the medium. The concentrations of GSK3 $\beta$ inhibitors used in this study are within the range of pharmacologically relevant doses, as previously reported ${ }^{30,31,34}$. At designated time points, the relative numbers of viable cells were determined using the WST-8 (4-[3-(4-iodophenyl)2-(4-nitrophenyl)-2H-5-tetrazolio]-1,3-benzene disulfonate) assay kit (Cell Counting Kit-8; Dojindo). After treatment with DMSO or GSK3 $\beta$ inhibitor, the relative numbers of proliferating and apoptotic cells were determined using the Click-iT Plus 5-ethynyl-2'-deoxyuridine (EdU) Alexa Fluor 555 Imaging Kit (Thermo Fisher Scientific) and the Cellular DNA Fragmentation ELISA kit (Roche Diagnostics), respectively. Using fluorescence microscopy (Keyence BZ-X700 Analyzer, Version 1.3), proliferating cells positive for EdU in nuclei were scored following treatment with DMSO or with one of the GSK3 $\beta$ inhibitors. The mean percentage of cells positive for nuclear EdU in 5 microscopic fields was calculated with standard deviations (SDs). The occurrence of apoptosis was further shown by observing changes in cell-cycle fractions as described below.

RNA interference (RNAi). Small interfering RNA (siRNA) specific to human GSK3 $\beta$ (GSK3 $\beta$ Validated Stealth RNAi) and negative control siRNA (Stealth RNAi Negative Control Low GC duplex) were purchased from Invitrogen. The specificity of GSK3 $\beta$-specific siRNA was confirmed in our previous studies ${ }^{29,35}$. Cells were transfected with $20 \mathrm{nmol} / \mathrm{L}$ of either siRNA using Lipofectamine RNAiMAX (Invitrogen). The effect of RNAi on GSK3 $\beta$ expression was determined by Western blotting using an antibody that recognizes both GSK3 $\alpha$ and GSK3 $\beta$ (Millipore). To examine the effect of GSK3 $\beta$ RNAi on cell survival, proliferation and apoptosis, cells were 
transfected with $20 \mathrm{nmol} / \mathrm{L}$ of control or GSK3 $\beta$-specific siRNA. At $72 \mathrm{~h}$ after transfection, the relative numbers of viable, proliferating and apoptotic cells were measured as described above.

Analysis of cell cycle profile. The cell cycle profile was analyzed by fluorescence-activated cell sorting (FACS) as described previously ${ }^{36}$. Briefly, ESCC cells were treated with DMSO, $25 \mu \mathrm{mol} / \mathrm{L}$ AR-A014418 or SB-216763 for $48 \mathrm{~h}$, or transfected with negative control siRNA or GSK3 $\beta$-specific siRNA for $72 \mathrm{~h}$. The cells were then trypsinized, washed twice with phosphate buffered saline (PBS), and fixed in $70 \%$ ethanol at $-20{ }^{\circ} \mathrm{C}$ overnight. Fixed cells were suspended in PBS containing $50 \mu \mathrm{g} / \mathrm{mL}$ RNase A (Nacalai Tesque) and $50 \mu \mathrm{g} / \mathrm{mL}$ propidium iodide (PI) (Sigma-Aldrich). Cellular DNA content was analyzed using a FACS Canto II with FACSDiva software (Version 8.0, BD Bioscience).

Animal study. The effect of GSK3 $\beta$ inhibition on tumor proliferation was examined on ESCC TE- 8 cell xenografts in athymic mice. A total of $1 \times 10^{6} \mathrm{TE}-8$ cells suspended in $50 \mu \mathrm{L}$ of PBS were subcutaneously inoculated into each of $25 \mathrm{BALB} / \mathrm{c}$ athymic mice (Charles River Laboratories, Japan). Mice were randomly assigned to five groups and given tri-weekly intraperitoneal (i.p.) injections of DMSO or of the GSK3 $\beta$ inhibitors AR-A014418 at different doses $(2 \mathrm{mg} / \mathrm{kg}$ and $5 \mathrm{mg} / \mathrm{kg}$ body weight) or LY2090314 (1 mg/kg and $2.5 \mathrm{mg} / \mathrm{kg}$ body weight) for 5 weeks. Assuming that total body fluid in mice accounts for about $60 \%$ of their body weight, AR-A014418 doses of $2 \mathrm{mg} / \mathrm{kg}$ and $5 \mathrm{mg} / \mathrm{kg}$ body weight correspond to concentrations of approximately $10 \mu \mathrm{mol} / \mathrm{L}$ and $25 \mu \mathrm{mol} / \mathrm{L}$ in culture media respectively ${ }^{29}$, and LY2090314 doses of $1 \mathrm{mg} / \mathrm{kg}$ and $2.5 \mathrm{mg} / \mathrm{kg}$ body weight correspond to concentrations of approximately $2 \mu \mathrm{mol} / \mathrm{L}$ and $5 \mu \mathrm{mol} / \mathrm{L}$, respectively. These are known pharmacological doses for these agents ${ }^{30,34}$. Throughout the experiment, all mice were carefully observed each day for adverse events and their body weight and tumors (in two dimensions) were measured twice a week. Tumor volume $\left(\mathrm{cm}^{3}\right)$ was calculated using the formula: $0.5 \times \mathrm{S}^{2} \times \mathrm{L}$, where $\mathrm{S}$ is the smallest tumor diameter $(\mathrm{cm})$ and $\mathrm{L}$ is the largest $(\mathrm{cm})^{29}$. The design and protocol of animal experiment and changes in body weights of animals during treatment are shown in the Supplementary Information, Fig. S1. All animal experiments were undertaken according to Japanese animal ethics guidelines ${ }^{37}$. The protocol was approved by the Institute for Experimental Animal Work, Kanazawa University Advanced Science Research Center.

At necropsy, tumors were removed and divided into three parts for fresh frozen storage, fixed in $10 \%$ neutralbuffered formalin or fixed in $4 \%$ paraformaldehyde and paraffin embedded for biochemical, histopathologic and immunohistochemical/immunofluorescence staining, respectively. Expression levels for GSK3 $\beta$, cyclin D1 and pGSK $3 \beta^{\mathrm{Y} 216}$ were evaluated by Western blotting for protein extracts from frozen tumor specimens as described above. Paraffin sections of the tumors were stained with HE for histopathologic examination by a certified pathologist (H.S.). Representative sections of the tumors were immunostained with antibodies against GSK3 $\beta$ (diluted 1:500; Cell Signaling Technology), pGSK3 $\beta^{\mathrm{Y} 216}$ (diluted 1:500; Cell Signaling Technology), GS (diluted 1:200, Cell Signaling Technology), pGS ${ }^{\text {S641 }}$ (diluted 1:200, Cell Signaling Technology), cyclin D1 (diluted 1:500; Cell Signaling Technology) and Ki-67 (diluted 1:700; Thermo Fisher Scientific) by the ABC method as described above. Apoptosis was detected in tumor xenografts by the terminal deoxynucleotidyl transferase-mediated dUTP nick end labeling (TUNEL) method using the In Situ Apoptosis Detection TUNEL kit (Takara). The stained tissue sections were observed using Keyence BZ-X700 Analyzer (Version 1.3). Tumor cells from 5 microscopic fields were scored for GSK3 $\beta$, pGSK3 $\beta^{\mathrm{Y} 216}$, GS, pGS ${ }^{\mathrm{S} 641}$, cyclin D1 or TUNEL. The mean percentages of positive cells were calculated with SDs and compared between the tumors of mice treated with DMSO and GSK3 $\beta$ inhibitors at different doses. Apoptosis in tumors was further evaluated by immunofluorescence staining of paraformaldehyde-fixed tumor sections with antibodies against PARP (1:500, Cell Signaling Technology) and c-PARP (1:500, Cell Signaling Technology) followed by nuclear staining with 4',6-diamidino-2-phenylindole (DAPI; H-1200, Vector Laboratories). Immunofluorescence images were observed and captured using Keyence BZ-X700 Analyzer (Version 1.3).

Statistical analysis. The Student's t test was used to determine statistical differences for the data, with a $P$ value of $<0.05$ considered to be statistically significant. IHC scores between normal tissues and tumors of ESCC patients were statistically analyzed by One-way ANOVA test using GraphPad Prism 5.0 (GraphPad Software, Inc. CA) and compared with clinical and pathologic characteristics by Chi-square test.

\section{Results}

Expression and phosphorylation-dependent activity of GSK3 $\beta$ in ESCC cells and patient tumors. The expression levels of GSK3 $\beta$ and its Y216 phosphorylated fraction (pGSK3 $\beta^{\mathrm{Y} 216}$, active form) were higher in all ESCC cell lines compared to normal esophageal squamous TYNEK-3 cells (Fig. 1A), with less detectable S9 phosphorylation (pGSK3 $\beta^{\text {S9 }}$, inactive form). Increased expression and activity of GSK3 $\beta$ in ESCC cells was also supported by the finding that 641 phosphorylation of GS (pGS ${ }^{\mathrm{S} 641}$, inactive form), the primary substrate of GSK3 $\beta^{15,16}$, was higher in ESCC than in TYNEK-3 cells (Supplementary Information, Fig. S2A). The levels of intracellular glycogen in ESCC cell lines were significantly lower than normal TYNEK-3 cells and were restored following treatment with GSK3 $\beta$ inhibitors (Supplementary Information, Fig. S2B).

We next examined the expression and phosphorylation of these enzymes in primary tumors and corresponding normal squamous mucosa from 46 ESCC patients using IHC. GSK3 $\beta$ expression and levels of pGSK3 $\beta^{\text {Y216 }}$ and $\mathrm{pGS}^{\mathrm{S} 641}$ in the primary tumors were increased in most cases compared with normal squamous mucosa. IHC scores were significantly higher in the tumors than in normal mucosa (Fig. 1B, Supplementary Information, Fig. S2C). By comparing with clinical and pathologic characteristics, tumor GSK3 $\beta$ expression was significantly correlated with venous invasion of tumor cells and with the presence of lymph node metastasis. Significant association was also found between the level of $\mathrm{pGSK} 3 \beta^{\mathrm{Y} 216}$ and the presence of lymph node metastasis (Table 1). 
A
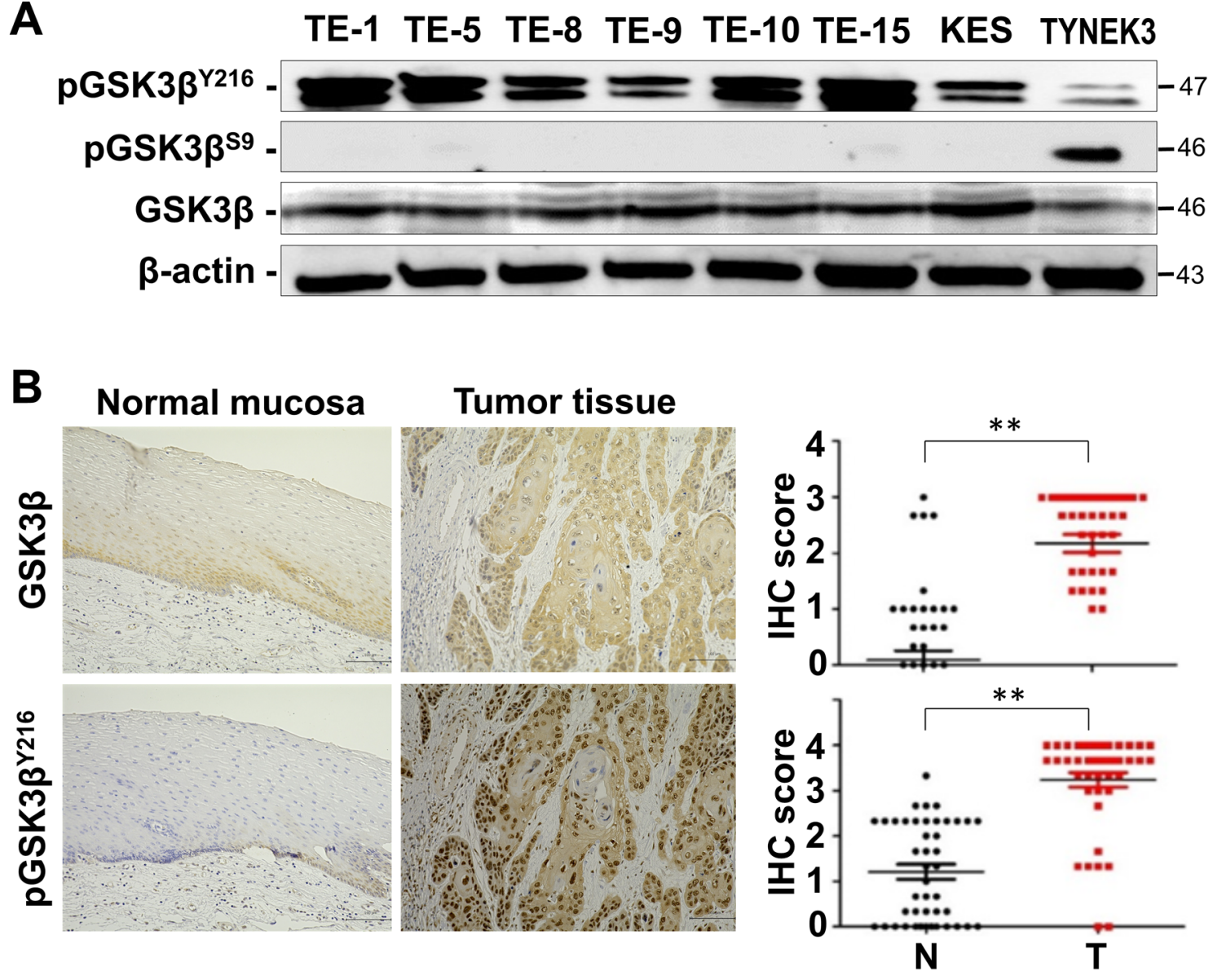

C

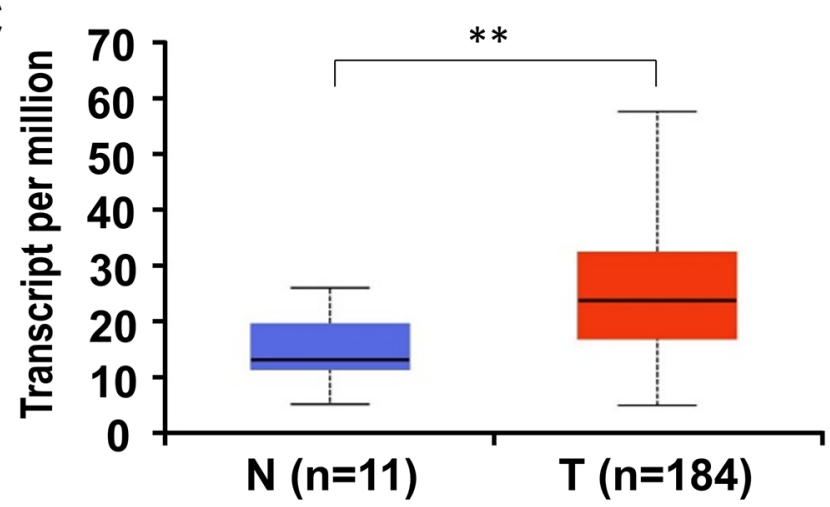

Figure 1. Comparative analysis for the expression and phosphorylation of GSK3 $\beta$ in human ESCC cells (TE-1, TE-5, TE-8, TE-9, TE-10, TE-15, KES), normal esophageal squamous epithelial cells (TYNEK-3), and normal squamous mucosa and primary tumors from ESCC patients. (A) Expression of GSK3 $\beta$ and of its phosphorylated forms ( $\mathrm{pGSK} 3 \beta^{\mathrm{S} 9}$, inactive form; pGSK3$\beta^{\mathrm{Y} 216}$, active form) were examined by Western blotting. $\beta$-actin expression was monitored as a loading control in each sample. (B) Representative findings for the expression of GSK3 $\beta$ and its Y216 phosphorylated fraction (pGSK3 $\beta^{\mathrm{Y} 216}$ ) in the primary tumor and corresponding normal squamous mucosa of ESCC patients. The scale bar indicates $100 \mu \mathrm{m}$ in length. Immunohistochemical images were captured using Keyence BZ-X700 Analyzer (Version 1.3). The two right hand graphs generated using GraphPad Prism 5.0 (GraphPad Software, Inc. CA) show statistical comparison of the immunohistochemistry (IHC) scores for GSK3 $\beta$ and pGSK3 $\beta^{\mathrm{Y} 216}$ between the primary tumor $(\mathrm{T})$ and normal mucosa $(\mathrm{N})$ of ESCC patients. A horizontal bar in each group shows the mean value of IHC scores. (C) Expression of GSK3 $\beta$ mRNA in normal esophageal tissues $(\mathrm{N})$ and primary ESCC tumor tissues (T) based on the TCGA database. The data was generated using the analysis tool UALCAN (https://ualcan.path.uab.edu/) ${ }^{33} . \mathrm{n}$, number of patients; ${ }^{*} P<0.01$. Full-length blots for $(\mathbf{A})$ are shown in Supplementary Information, Fig. S9. 


\begin{tabular}{|c|c|c|c|c|c|c|c|c|c|c|c|c|}
\hline \multirow[b]{2}{*}{ Parameters } & \multicolumn{3}{|c|}{ GSK3 $\beta$} & \multicolumn{3}{|c|}{ pGSK3 $\beta^{\mathrm{Y} 216}$} & \multicolumn{3}{|l|}{ GS } & \multicolumn{3}{|c|}{ pGS $^{\text {S641 }}$} \\
\hline & Low & High & $P$-value & Low & High & $P$-value & Low & High & $P$-value & Low & High & $P$-value \\
\hline \multicolumn{13}{|l|}{ Gender } \\
\hline Female & 4 & 5 & $P=0.634$ & 7 & 2 & $P=0.838$ & 1 & 8 & $P=0.447$ & 4 & 5 & $P=0.236$ \\
\hline Male & 11 & 26 & & 27 & 10 & & 5 & 32 & & 7 & 30 & \\
\hline \multicolumn{13}{|l|}{ Age (years) } \\
\hline$<60$ & 6 & 15 & $P=0.797$ & 12 & 9 & $P=0.176$ & 6 & 15 & $P=0.056$ & 6 & 15 & $P=0.571$ \\
\hline$\geq 60$ & 7 & 19 & & 20 & 8 & & 1 & 24 & & 5 & 23 & \\
\hline \multicolumn{13}{|l|}{\begin{tabular}{|l} 
Histology \\
\end{tabular}} \\
\hline WD & 3 & 13 & $P=0.65$ & 11 & 5 & $P=0.83$ & 2 & 14 & $P=0.75$ & 3 & 13 & $P=0.84$ \\
\hline MD & 4 & 14 & & 12 & 6 & & 4 & 16 & & 3 & 15 & \\
\hline PD & 4 & 8 & & 7 & 5 & & 3 & 10 & & 3 & 9 & \\
\hline \multicolumn{13}{|c|}{\begin{tabular}{|l|} 
Venous invasion \\
\end{tabular}} \\
\hline Absent & 9 & 13 & $P=0.024$ & 3 & 19 & $P=0.296$ & 1 & 21 & $P=0.259$ & 1 & 21 & $P=0.496$ \\
\hline Present & 2 & 22 & & 5 & 19 & & 2 & 22 & & 1 & 23 & \\
\hline \multicolumn{13}{|c|}{ LN metastasis } \\
\hline Absent & 9 & 11 & $P=0.009$ & 8 & 12 & $P=0.047$ & 10 & 10 & $P=0.026$ & 9 & 11 & $P=0.05$ \\
\hline Present & 2 & 24 & & 3 & 23 & & 4 & 22 & & 6 & 20 & \\
\hline \multicolumn{13}{|c|}{ Stage (TMN) } \\
\hline I & 5 & 7 & $P=0.479$ & 3 & 9 & $P=0.722$ & 4 & 8 & $P=0.23$ & 3 & 9 & $P=0.92$ \\
\hline II & 4 & 12 & & 2 & 14 & & 1 & 15 & & 3 & 13 & \\
\hline III & 1 & 7 & & 2 & 6 & & 1 & 7 & & 1 & 7 & \\
\hline IV & 2 & 8 & & 3 & 7 & & 1 & 9 & & 2 & 8 & \\
\hline $\mathrm{I}+\mathrm{II}$ & 9 & 19 & $P=0.401$ & 5 & 25 & $P=0.195$ & 5 & 23 & $P=0.798$ & 6 & 22 & $P=0.84$ \\
\hline III + IV & 3 & 15 & & 5 & 13 & & 2 & 16 & & 3 & 15 & \\
\hline
\end{tabular}

Table 1. Comparison of the levels of expression and phosphorylation of GSK3 $\beta$ and GS in the primary tumors with the clinicopathologic parameters of ESCC patients. GS glycogen synthase, GSK3 $\beta$ glycogen synthase kinase $3 \beta, L N$ lymph node, $M D$ moderately differentiated SCC, $P D$ poorly differentiated SCC, SCC squamous cell carcinoma, WD well differentiated SCC.

Levels of GSK3 $\beta$ and pGSK3 $3 \beta^{\mathrm{Y} 216}$ in the tumors tended to be associated with advanced tumor stages (III and IV), although this did not reach statistical significance $(P=0.22$; Table 1$)$. Similar trends were observed for the levels of GSK3 $\beta$ mRNA in normal and tumor tissues of ESCC patients referenced from the TCGA database (Fig. 1C, Supplementary Information, Fig. S3). Together, the results obtained with the ESCC cells and primary tumors suggest that deregulated expression and activity of GSK3 $\beta$ is a characteristic of ESCC and facilitates its progression.

Effect of GSK3 $\beta$ inhibition on ESCC cell survival, proliferation and apoptosis. To address our hypothesis of a putative tumor-promoting role for GSK $3 \beta$ in ESCC, the biological outcome resulting from GSK3 $\beta$ inhibition was examined in terms of tumor cell survival, proliferation and apoptosis. Treatment with the GSK3 $\beta$ inhibitors (AR-A014418, SB-216763) reduced viability of all ESCC cells in a dose- and time-dependent manner, while sparing normal TYNEK-3 cells (Fig. 2A, Supplementary Information, Fig. S4A). The IC ${ }_{50}$ values of both inhibitors at $48 \mathrm{~h}$ after treatment were within the reported pharmacological dose range $(1-100 \mu \mathrm{mol} / \mathrm{L})$ for AR-A $014418^{30}$ and SB-216763 ${ }^{31}$. These GSK3 $\beta$ inhibitors decreased the number of EdU-positive proliferating cells (Fig. 2B, Supplementary Information, Fig. S5A) and increased the incidence of apoptosis in ESCC cells (Fig. 2C). Treatment with LY2090314 within the reported pharmacological dose range showed therapeutic effects against ESCC cells that were comparable to AR-A014418 and SB-216763. (Supplementary information, Fig. S6). Induction of apoptosis by GSK3 $\beta$ inhibition was further confirmed by increases in the fraction of c-PARP (Fig. 2D) and the sub-G0/G1 fraction in cell cycle analysis (Fig. 3A,B, Supplementary Information, Fig. S7A). Similar effects were observed in ESCC cells following depletion of GSK3 $\beta$ by siRNA transfection (Fig. 2B,C, Supplementary Information, Fig. S4B,C). These results indicate that ESCC depends on aberrant GSK3 $\beta$ activity for tumor cell survival and proliferation and for evasion of apoptosis, thus implicating this kinase as a potential therapeutic target in ESCC.

Effects of GSK3 $\beta$ inhibition on cell cycle profile and on cell cycle regulatory molecules. To investigate the mechanism by which GSK3 $\beta$ sustains tumor cell survival and proliferation, we examined the effect of GSK3 $\beta$ inhibition on the cell cycle profile in ESCC cells. FACS analysis showed that treatment of cells with $25 \mu \mathrm{mol} / \mathrm{L}$ GSK3 $\beta$ inhibitors for $48 \mathrm{~h}$ decreased the G0/G1-phase fraction, while increasing G2/M-phase and sub-G0/G1 fractions in TE-8, TE-5, and TE-10 cells (Fig. 3A,B, Supplementary Information, Fig. S7A). 
These effects were reproduced by treatment of the same cells with GSK3 $\beta$-specific siRNA transfection (Fig. 3B, Supplementary Information, Fig. S7B). Thus, GSK3 $\beta$ inhibition decreased cell entry into the G1 phase and induced apoptosis (corresponding to the sub-G0/G1 fraction), as well as resulting in cell cycle arrest at the G2/M phase. In line with these effects, inhibition of GSK3 $\beta$ decreased the expression of cyclin D1 and CDK4, which as a complex enable cells to enter G1-phase ${ }^{38}$. Inhibition of GSK3 $\beta$ also increased the expression of cyclin B1 (Fig. 3C,D), which is involved in the G2/M phase transition from the S phase ${ }^{38}$. These alterations in cell cycle profiles and in the expression of cell cycle regulatory molecules are consistent with our previous study showing that inhibition of GSK3 $\beta$ induced mitotic catastrophe following G2/M-phase cell cycle arrest in colorectal cancer cells, ultimately resulting in apoptosi ${ }^{36}$. This also suggests the large majority of ESCC cells with GSK3 $\beta$ inhibition in the G2/M phase undergo apoptosis and only cells that survive enter the next round of cell cycle, which is reflected by decreased EdU labeling by GSK3 $\beta$ inhibition (Fig. 2B, Supplementary Figs. S5, S6). Collectively, these results indicate that GSK3 $\beta$-mediated regulation of cell cycle progression via cyclin D1, CDK4 and cyclin $\mathrm{B} 1$ is responsible for tumor cell survival and proliferation in ESCC.

Effect of GSK3 $\beta$ inhibitors on ESCC xenografts in mice. Prerequisites for clinical translation of a therapy in the investigational phase include its efficacy against the target disease as well as its safety in rodents. In this study, we tested the efficacy of GSK3 $\beta$ inhibitors against TE- 8 cell xenograft tumors in mice. The inhibitors included AR-A014418 and LY2090314, with the latter having previously been tested in clinical trials ${ }^{39,40}$. Prior to the animal experiments, cell survival assays showed a dose- and time-dependent effect of LY2090314 against TE- 8 cells, with $\mathrm{IC}_{50}=2.18 \mu \mathrm{mol} / \mathrm{L}$ after treatment for $72 \mathrm{~h}$ (Supplementary Information, Fig. S6). Based on the $\mathrm{IC}_{50}$ concentration for LY2090314 used in vitro in the present study and in previous preclinical ${ }^{41}$ and clinical studies $^{39,40}$, we used doses of $1 \mathrm{mg} / \mathrm{kg}$ and $2.5 \mathrm{mg} / \mathrm{kg}$ body weight in the xenograft study.

Compared to DMSO, treatment of mice with AR-A014418 and LY2090314 significantly reduced the xenograft tumor volume in a dose- and time-dependent manner (Fig. 4A,B). Following treatment for 4 weeks, we sacrificed two DMSO-treated mice that showed a body weight loss of $<18 \mathrm{~g}$ (Supplementary Information, Fig. S1B) according to the animal ethics guidelines. Throughout the scheduled treatment period, no obvious detrimental effects or adverse events were observed in mice undergoing treatment with the GSK3 $\beta$ inhibitors. At necropsy, gross observation and histologic examination showed no pathologic findings and no primary or metastatic tumors in the vital organs including lungs, liver, pancreas and kidneys of all mice (not shown).

We compared the level of pGSK3 $\beta^{\mathrm{Y} 216}$ (active form) in the tumors of mice treated with DMSO or with the

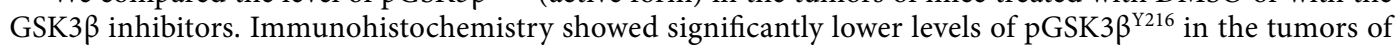
inhibitor-treated mice (Fig. 5), consistent with the results from Western blotting (Supplementary Information, Fig. S8A). These findings indicate that decreased pGSK3 $\beta^{\mathrm{Y} 216}$ level is probably a consequence of the GSK3 $\beta$ inhibitors acting against GSK $3 \beta$ in tumor cells in mice, although the primary mechanism of action of these inhibitors is to compete with ATP for the ATP-binding pocket in GSK3 $\beta^{30,34}$. Similar to ESCC cell cultures (Figs. 2B-D, 3 C, Supplementary Information, Fig. S5, S6), the GSK3 $\beta$ inhibitors significantly reduced tumor cell proliferation (Ki-67-positive cells), pGS ${ }^{\mathrm{S} 641}$ level and cyclin D1 expression, while inducing apoptosis (TUNEL- and c-PARPpositive cells) (Fig. 5, Supplementary Information, Fig. S8B).

\section{Discussion}

Different treatment options for ESCC depend on the tumor stage and on patient tolerability to the treament ${ }^{2,5}$. Non-invasive and minimally invasive tumors with little risk of lymph node metastasis are rare and are amenable to endoscopic resection, radiofrequency ablation and photodynamic therapy. Patients with locally invasive ESCCs but no distant metastasis undergo transthoracic esophagectomy with lymphadenectomy. Patients with locally advanced and/or metastatic ESCC account for the vast majority of patients and require treatment with various combinations of chemotherapy, radiation and surgery. Recently, biological agents that target epidermal growth factor receptor (e.g., gefitinib) ${ }^{42}$ and programmed cell death protein 1 (PD-1) pathway (e.g., nivolumab ${ }^{43}$ have been tested for advanced ESCC patients who are refractory to multipronged therapy. However, the overall efficacy of these therapies has been low and the overall 5-year survival rate of ESCC patients is between 15 to $25 \%$. ESCC is the 6th leading cause of cancer-related mortality worldwide ${ }^{3-5,44}$ and the dismal outlook of this disease has led us to investigate the putative tumor-promoting role of GSK3 $\beta$ as a new therapeutic target in ESCC.

Based on its physiological functions against major proto-oncogenic pathways driven by Wnt/ $\beta$-catenin, hedgehog, notch and c-Myc signaling, as well as against epithelial-to-mesenchymal transition, GSK3 $\beta$ has long been recognized to suppress tumor development and progression ${ }^{18,22}$. Several previous studies on the tumorsuppressive roles of GSK3 $\beta$ in various oncogenic pathways showed that it was inactivated mostly through S9 phosphorylation. However, there was no evidence that active GSK3 $\beta$ suppresses the development and progression of tumors by disrupting the major proto-oncogenic (e.g., Wnt $/ \beta$-catenin) pathways (reviewed in Ref. ${ }^{20}$ ). It was reported that $\mathrm{Axl}$ oncoprotein promotes the development and progression of ESCC via inactivation of GSK3 $\beta$ and activation of the NF- $\kappa$ B pathway ${ }^{45}$. However, this study did not measure the basal levels of expression and/ or activity of GSK3 $\beta$ in the tumor cells, nor did it investigate the direct effects of GSK3 $\beta$ inhibition on tumor cell survival, proliferation and apoptosis. In contrast, many previous studies have demonstrated direct tumorpromoting roles of GSK3 $\beta$ in at least 25 different cancer types (reviewed in Ref. ${ }^{23}$ ).

In the present study, we found that expression and activity of GSK3 $\beta$ in ESCC cell lines and primary tumors was higher than in normal esophageal squamous mucosal cells and tissues. Consistent with previous studies by our group and others (reviewed in Refs. ${ }^{18-21,23}$ ), inhibition of GSK3 $\beta$ attenuated tumor cell survival and proliferation and induced apoptosis in ESCC cells and in xenograft tumors. Previous studies showed a similar 
A

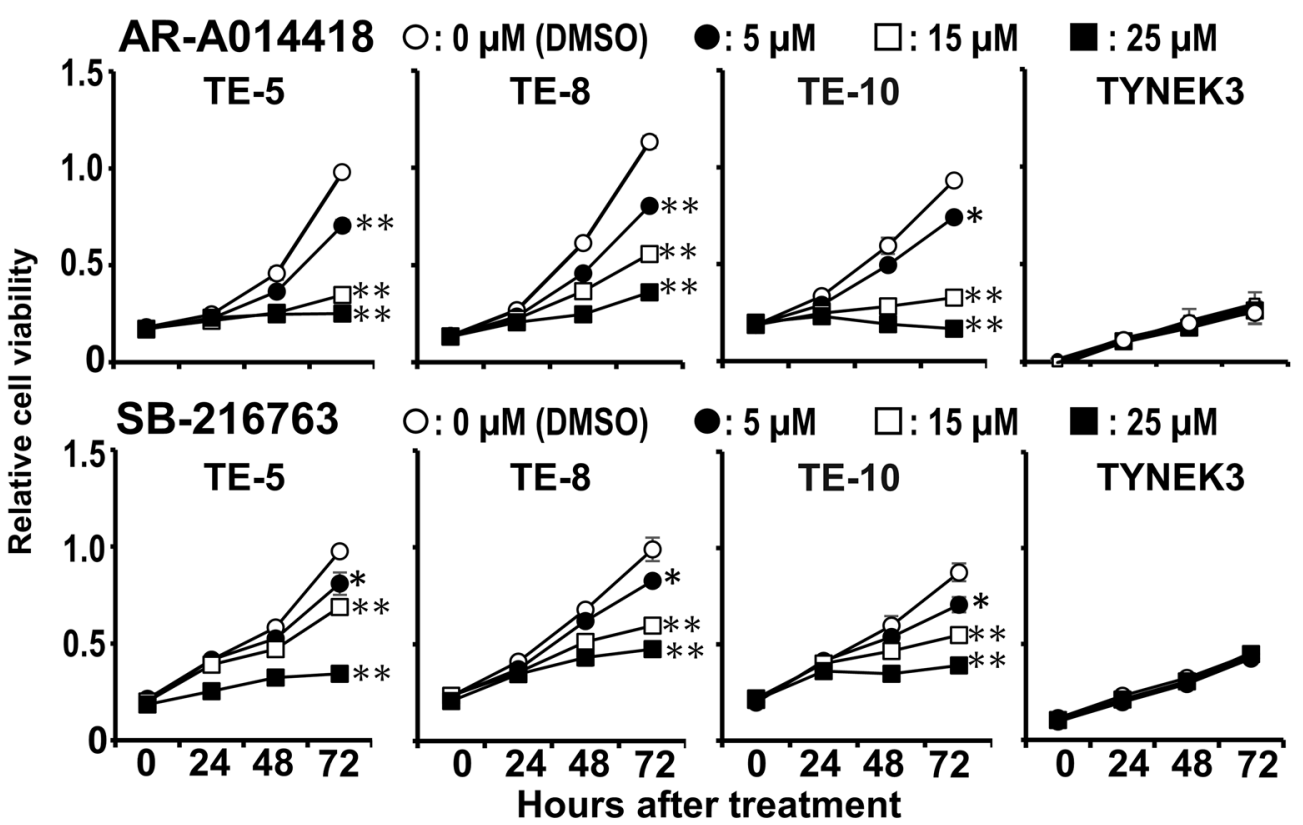

B

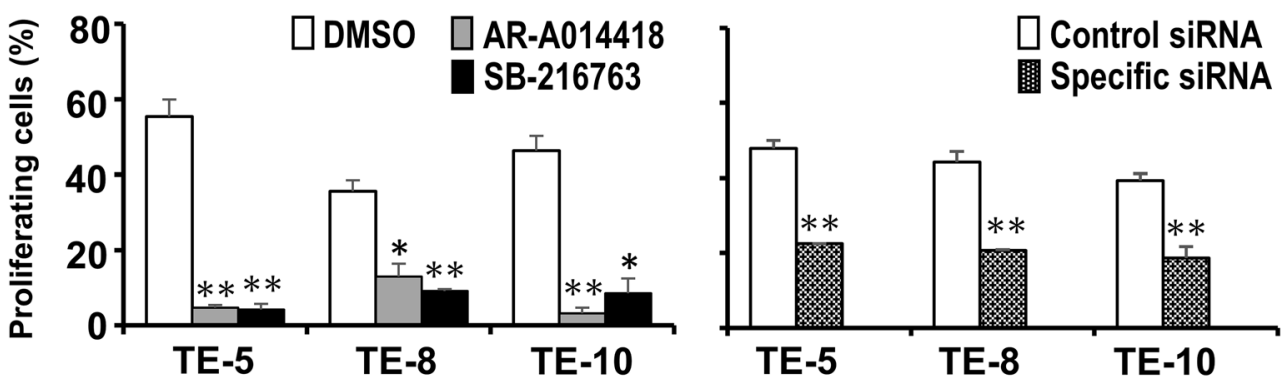

C

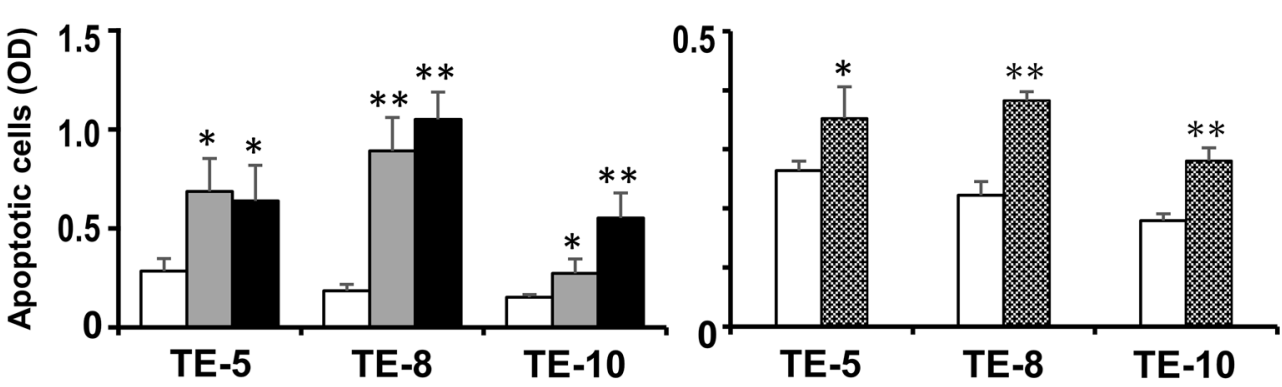

D

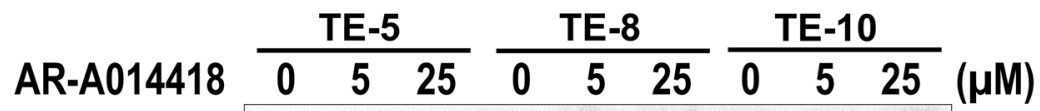
cleaved PARP - 15

PARP $=--\infty-\infty-116$

B-actin $=-43$ 
4Figure 2. Effects of GSK3 $\beta$ inhibition on cell survival, proliferation and apoptosis in ESCC (TE-5, TE-8, TE-10) and normal esophageal squamous TYNEK-3 cells. (A) The respective ESCC cells and TYNEK-3 cells were treated with DMSO or the indicated concentration of AR-A014418 or SB-216763 for the designated times. The relative number of viable cells at each time point was examined by WST- 8 assay. Mean values with standard deviations of triplicate experiments were compared between cells treated with DMSO and the indicated GSK3 $\beta$ inhibitor at different concentrations. ${ }^{\star} P<0.05,{ }^{\star \star} P<0.01$. (B) The incidence of EdU-positive proliferating cells was compared between ESCC cells treated with DMSO (open column), $25 \mu \mathrm{mol} / \mathrm{L}$ AR-A014418 (gray column) and SB-216763 (closed column) for $24 \mathrm{~h}$ (left panel), and between the cells transfected with $20 \mathrm{nmol} / \mathrm{L}$ control (open column) and GSK3 $\beta$-specific siRNA (dotted column) for $72 \mathrm{~h}$ (right panel). The mean percentages of EdU-positive proliferating cells in 5 fluorescence microscopy fields (shown in Supplementary Information, Fig. S5) were calculated with SDs and statistically compared. (C) The mean relative number \pm SDs of apoptotic cells measured by DNA fragmentation assay in triplicate was compared between ESCC cells with the same treatment as shown in $\mathbf{B}$. $(\mathbf{B}, \mathbf{C}){ }^{\star} P<0.05$; ${ }^{*} P<0.01$. (D) Western blotting analysis for the amount of PARP and c-PARP in ESCC cells treated with DMSO or the indicated concentrations of AR-A014418 for $24 \mathrm{~h}$. The amount of each protein sample was monitored by the expression of $\beta$-actin. Full-length blots for (D) are shown in Supplementary Information, Fig. S9.

A

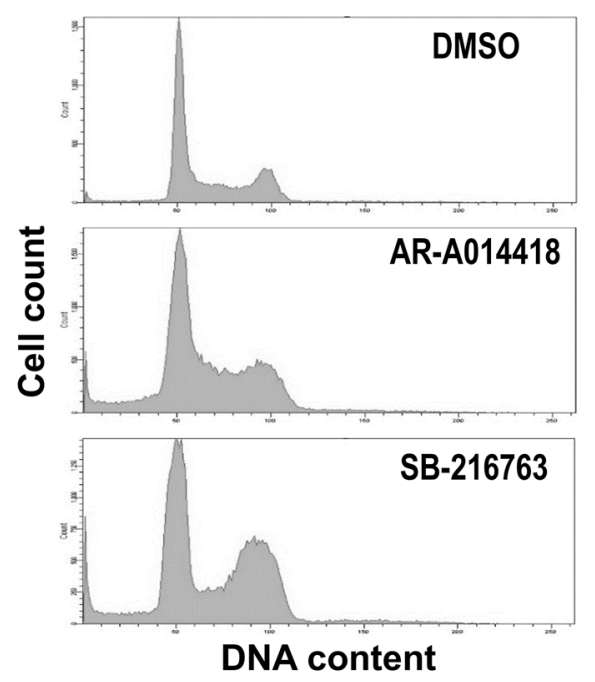

C

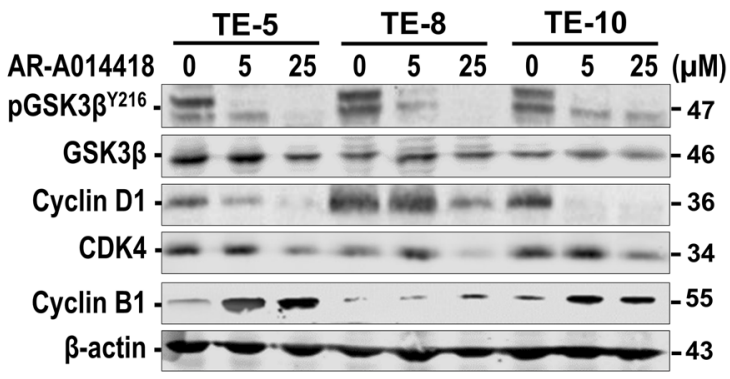

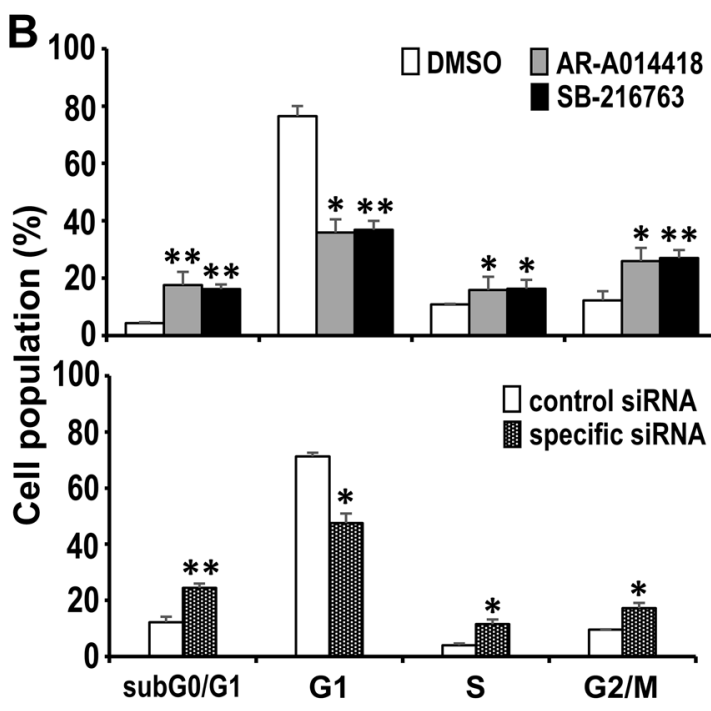

D

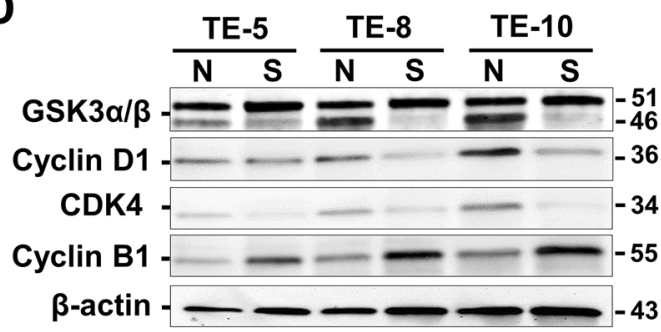

Figure 3. Effects of GSK3 $\beta$ inhibition on the cell cycle profiles and expression of cell cycle-regulating molecules in ESCC cells. (A) Representative flow cytometry findings of cell cycle profile of TE-8 cells treated with DMSO, $25 \mu \mathrm{mol} / \mathrm{L}$ AR-A014418 or SB-216763 for $48 \mathrm{~h}$. The data were generated using a FACS Canto II (BD Biosciences). (B) Comparison of DNA histograms for each cell cycle fraction of TE-8 cells treated with DMSO (open column), 25 mol/L AR-A014418 (gray column) or SB-216763 (closed column), or cells transfected for $72 \mathrm{~h}$ with non-specific (open column) or GSK3 $\beta$-specific siRNA (dotted column), respectively. Cellular DNA content was analyzed using FACSDiva software (Version 8.0, BD Bioscience). Data are the mean percentages of cell populations in the respective cell cycle phases with SDs in five separate tests. ${ }^{\star} P<0.05$; ${ }^{*} P<0.01$. (C) Western blotting analysis for expression of GSK3 $\beta$, cyclin D1, CDK4 and cyclin B1 and GSK3 $\beta$ Y216 phosphorylation (pGSK3 $\beta^{\text {Y216 }}$ ) in ESCC cells treated with the indicated concentrations of AR-A014418 for $48 \mathrm{~h}$. (D) Western blotting analysis for expression of GSK3 $\alpha / \beta$, cyclin D1, CDK4 and cyclin B1 in ESCC cells transfected with non-specific (N) or GSK3 $\beta$-specific (S) siRNA, respectively, for $72 \mathrm{~h}$. (C, D) The amount of each protein sample was monitored by the expression of $\beta$-actin. Full-length blots for $(\mathbf{C}, \mathbf{D})$ are shown in Supplementary Information, Fig. S9. 

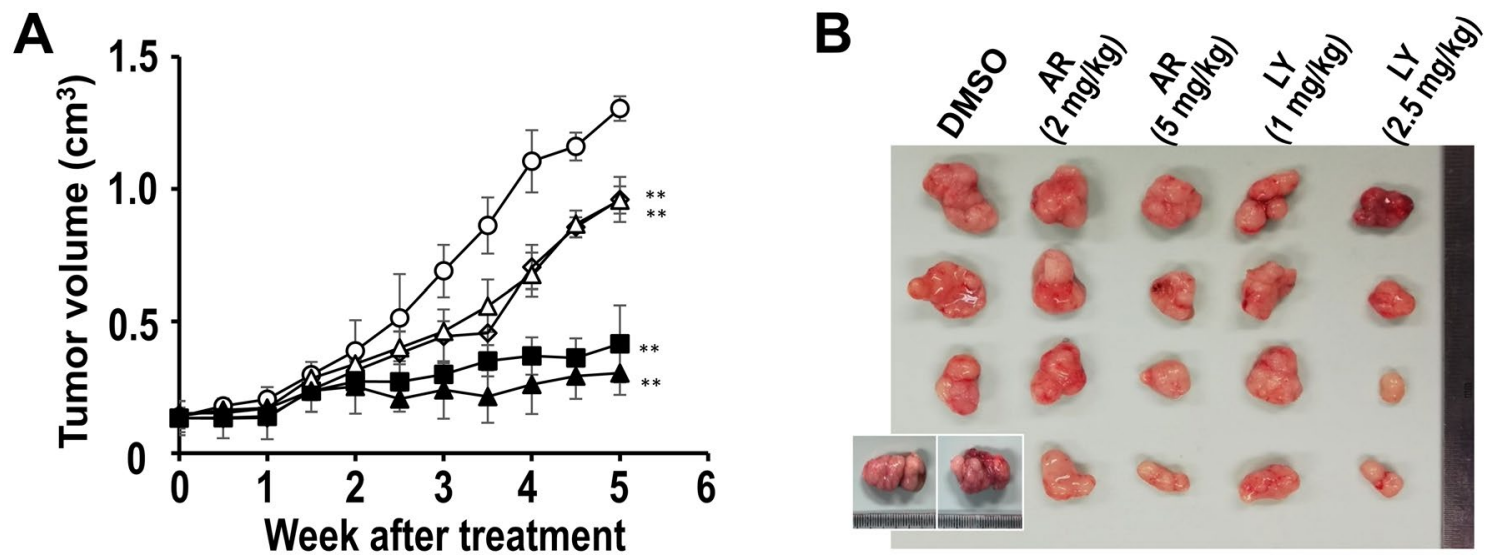

Figure 4. Effect of GSK3 $\beta$ inhibitors on proliferation of ESCC cell xenograft tumors in mice. (A) Time course of the effects of DMSO (open circle), AR-A014418 ( $2 \mathrm{mg} / \mathrm{kg}$ body weight, open square; $5 \mathrm{mg} / \mathrm{kg}$ body weight, closed square), and LY2090314 (1 mg/kg body weight, open triangle; $2.5 \mathrm{mg} / \mathrm{kg}$ body weight, closed triangle) on tumor size of TE-8 cell xenografts in mice. (B) Gross appearance of xenograft tumors removed at autopsy from mice after 5 weeks of treatment with different doses of AR-A014418 (AR) or LY2090314 (LY). The left lower insets show the tumors removed from two mice 4 weeks after treatment with DMSO following animal experimentation ethics guidelines as described in the "Results". ${ }^{*} P<0.01$.

therapeutic effect of lithium, a non-specific and ATP-non-competitive GSK3 inhibitor, against ESCC ${ }^{46,47}$. Here we showed no harmful effects of pharmacological GSK3 $\beta$ inhibitors on normal human esophageal squamous cells and on the esophagus and vital organs of mice. Taken together, the present study reinforces the notion that GSK3 $\beta$ is a potential therapeutic target in ESCC, thereby including this as another tumor type susceptible to GSK3 $\beta$-targeted therapy ${ }^{19,21}$.

Uncontrolled cell cycle progression is one of the biological hallmarks of cancer. Novel cancer therapeutics include agents that target microtubule dynamics and inhibitors of mitotic kinases such as cyclin-dependent kinases $(\mathrm{CDKs})^{38,48}$. In the present study, the therapeutic effects of GSK3 $\beta$ inhibition in ESCC cells included cell cycle arrest at G0/G1- and G2/M-phase, decreased expression of cyclin D1 and CDK4, and increased cyclin B1 expression. We and others have previously shown that inhibition of GSK3 $\beta$ in human colon and breast cancer cells induced mitotic catastrophe by disturbing centrosome dynamics and the assembly of spindle apparatus, with the cells ultimately undergoing apoptosis ${ }^{36,49}$. Overall, our results suggest that ESCC cells depend on deregulated GSK3 $\beta$ for their survival and proliferation via cyclin D1 and CDK4-mediated G0/G1-phase cell cycle progression and G2/M-phase cell cycle transition. As reviewed recently by our group ${ }^{23}$, the tumor-promoting roles of GSK3 $\beta$ involve diverse arrays of pro-oncogenic pathways, suggesting a need for future studies to clarify the distinct biological mechanism(s) by which GSK3 $\beta$ participates in the progression of ESCC.

One of the earliest biochemical changes during ESC carcinogenesis is the disappearance of glycogen in transformed cells. Loss of glycogen in the early stages of squamous cell carcinogenesis was first observed in uterine cervical squamous mucosa in $1933^{50}$. This fundamental biochemical characteristic enables the Schiller test and Lugol's dye endoscopy for early diagnosis of squamous cell carcinoma in the uterine cervix and esophagus ${ }^{2,50}$. However, the biological mechanism for glycogen loss is not yet fully understood. In the present study we observed the level of $\mathrm{pGS}^{\mathrm{S641}}$ was higher in ESCC cells and primary tumors than in normal TYNEK-3 cells and normal squamous mucosa, indicating the inactivation of GS in ESCC. This coincided with increased pGSK3 $\beta^{\mathrm{Y} 216}$ (active form) and decreased pGSK3 $\beta^{\mathrm{Sg}}$ (inactive form) levels in ESCC cells and tumors. These observations may explain the depletion of glycogen in ESCC cells.

Among the biological hallmark characteristics of cancer, aberrant glycolysis as represented by the Warburg effect is the strongest and most critical selective pressure for cellular transformation and malignant evolution in the majority of cancer types ${ }^{51-53}$, including ESCC ${ }^{54}$. The substrates of GSK3 $\beta$ include a number of key metabolic enzymes, suggesting this kinase could have broad control over various physiological and pathological metabolic pathways ${ }^{15,16}$. The primary role of GSK3 $\beta$ is to control GS activity via S641 phosphorylation, thus acting at the bifurcation between glycogen synthesis and glycolysis, the two major pathways of glucose/glycogen metabolism. Preliminary findings from the present study showed that intracellular constitutive levels of glycogen in ESCC cells were significantly lower than in normal TYNEK-3 cells, but were restored following treatment with GSK3 $\beta$ inhibitor. Accordingly, our observations suggest that deregulated GSK3 $\beta$ may shift ESCC cell metabolism from glycogenesis to the glycolytic pathway. The latter fuels the synthesis of biomacromolecules (nucleic acids, amino acids, lipids) and energy (ATP) production, both of which are mandatory for sustained cell survival and proliferation. Our results also provide novel insight into how glucose metabolism is reprogrammed in cancer cells ${ }^{55}$. 

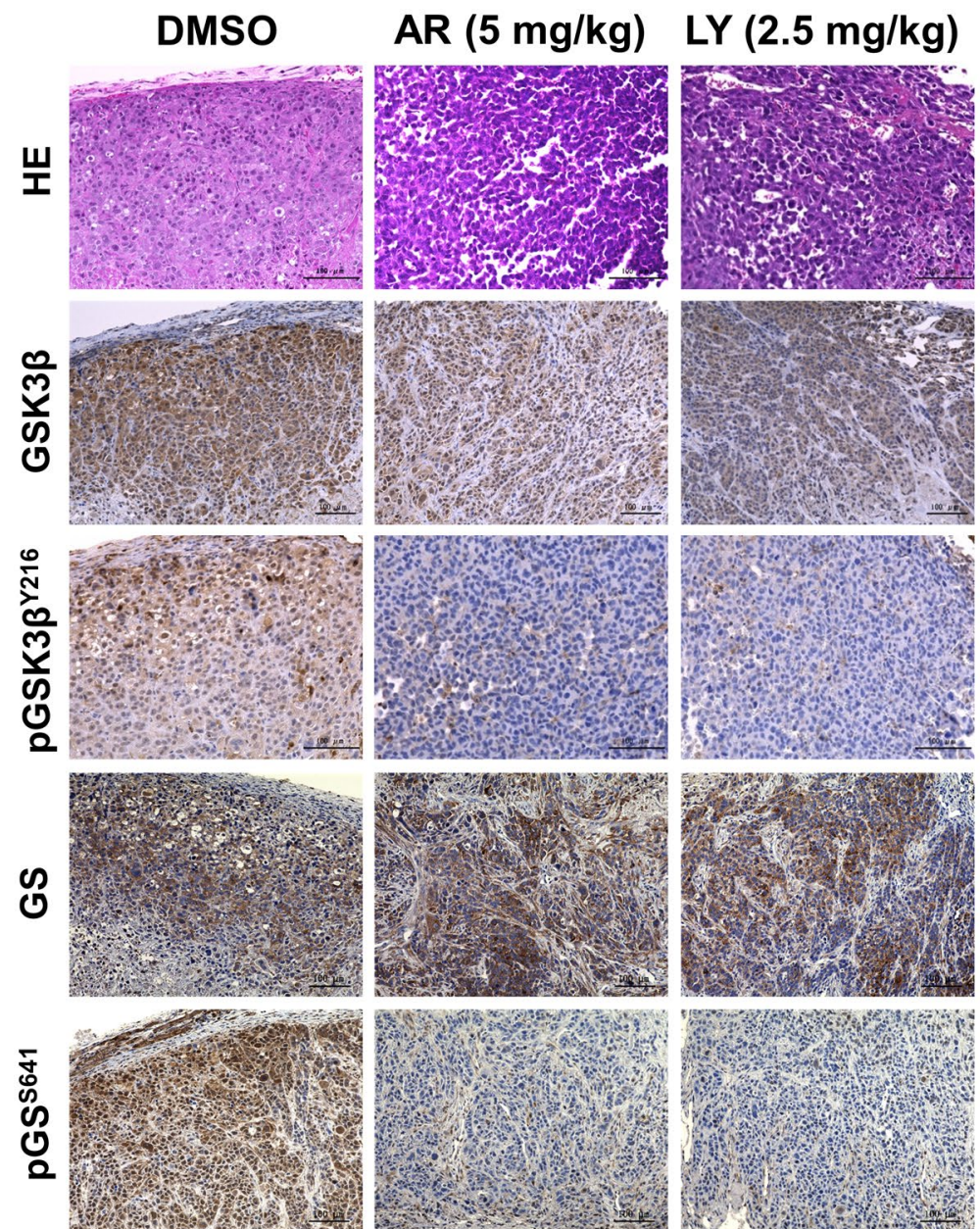

$\%$ positive cells
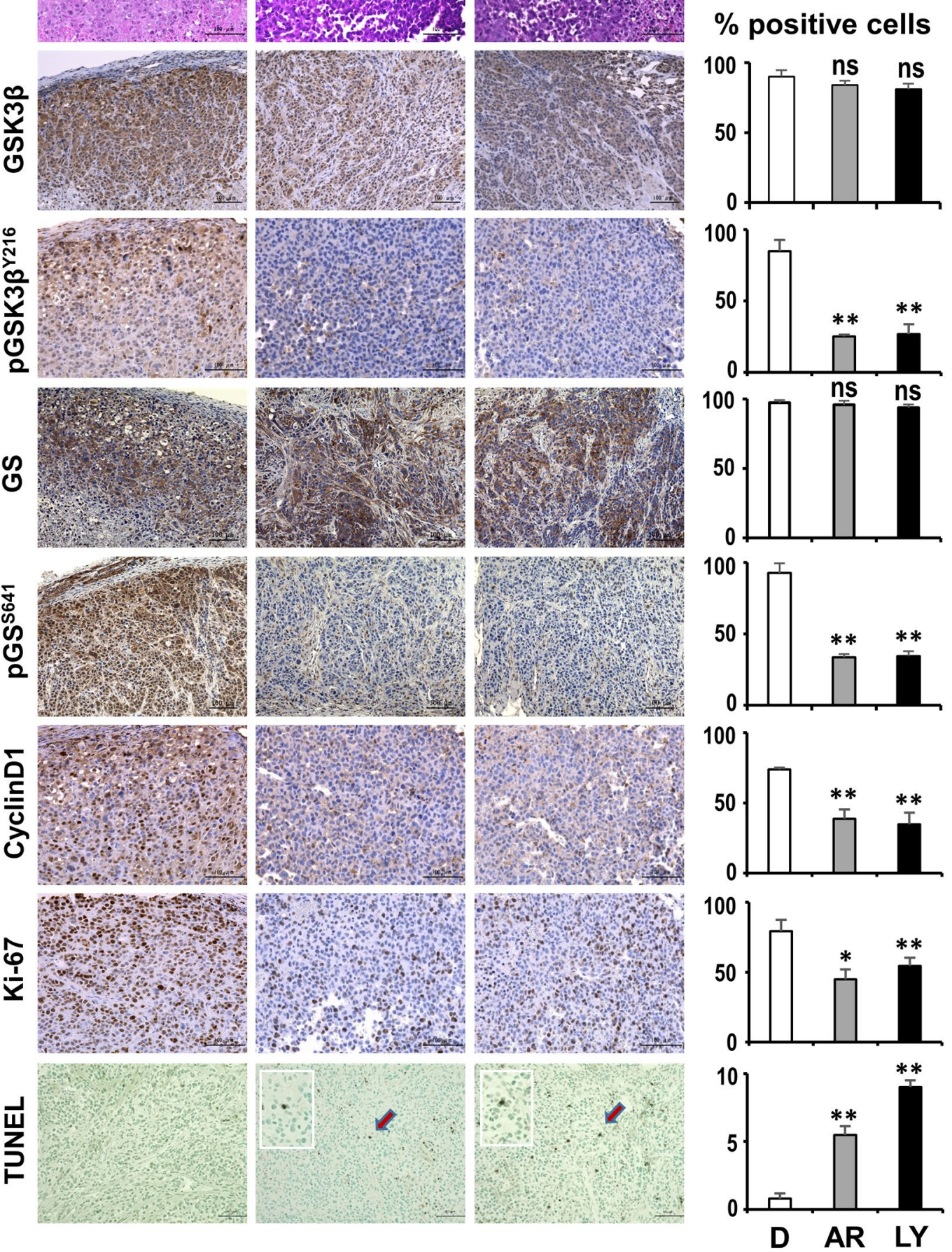

Figure 5. Representative histological, immunohistochemical and histochemical findings of xenograft tumors from mice treated with DMSO, $5 \mathrm{mg} / \mathrm{kg}$ body weight AR-A014418 (AR) or $2.5 \mathrm{mg} / \mathrm{kg}$ body weight LY2090314 (LY). Serial paraffin sections of the respective tumors were stained with hematoxylin and eosin (HE), immunostained for GSK3 $\beta$, pGSK3 $\beta^{\mathrm{Y} 216}, \mathrm{GS}, \mathrm{pGS}^{\mathrm{S} 641}$, cyclin D1 and Ki-67, and histochemically stained by the TUNEL method. A scale bar in each panel indicates $100 \mu \mathrm{m}$. Histological, immunohistochemical and histochemical images were captured using Keyence BZ-X700 Analyzer (Version 1.3). The graphs on the right side show statistical comparison of the mean percentages with SDs of tumor cells positive for the corresponding molecules, and TUNEL results for xenograft tumors from mice treated with DMSO, AR or LY. ${ }^{\star} P<0.05$; ${ }^{* *} P<0.01$. 
Received: 27 February 2020; Accepted: 26 June 2020

Published online: 16 July 2020

\section{References}

1. Rustgi, A. K. \& El-Serag, H. B. Esophageal carcinoma. N. Engl. J. Med. 371, 2499-2509. https://doi.org/10.1056/NEJMra1314530 (2014).

2. Ohashi, S. et al. Recent advances from basic and clinical studies of esophageal squamous cell carcinoma. Gastroenterology 149, 1700-1715. https://doi.org/10.1053/j.gastro.2015.08.054 (2015).

3. Watanabe, M. et al. Recent progress in multidisciplinary treatment for patients with esophageal cancer. Surg. Today. 50, 12-20. https://doi.org/10.1007/s00595-019-01878-7 (2020).

4. Lagergren, J., Smyth, E., Cunningham, D. \& Lagergren, P. Oesophageal cancer. Lancet 390, 2383-2396. https://doi.org/10.1016/ S0140-6736(17)31462-9 (2017).

5. Smyth, E. C. et al. Oesophageal cancer. Nat. Rev. Dis. Primers 3, 17048. https://doi.org/10.1038/nrdp.2017.48 (2017).

6. Abdo, J., Agrawal, D. K. \& Mittal, S. K. “Targeted” chemotherapy for esophageal cancer. Front. Oncol. 7, 63. https://doi.org/10.3389/ fonc.2017.00063 (2017).

7. Ilson, D. H. \& van Hillegersberg, R. Management of patients with adenocarcinoma or squamous cancer of the esophagus. Gastroenterology 154, 437-451. https://doi.org/10.1053/j.gastro.2017.09.048 (2018).

8. Atkins, M. B. \& Larkin, J. Immunotherapy combined or sequenced with targeted therapy in the treatment of solid tumors: current perspectives. J. Natl. Cancer Inst. 108, djv414. https://doi.org/10.1093/jnci/djv414 (2016).

9. Lordick, F. et al. Oesophageal cancer: ESMO Clinical Practice Guidelines for diagnosis, treatment and follow-up. Ann. Oncol. 27, v50-v57. https://doi.org/10.1093/annonc/mdw329 (2016).

10. Wang, V. E., Grandis, J. R. \& Ko, A. H. New strategies in esophageal carcinoma: translational insights from signaling pathways and immune checkpoints. Clin. Cancer Res. 22, 4283-4290. https://doi.org/10.1158/1078-0432.CCR-16-0292 (2016).

11. Song, Y. et al. Identification of genomic alterations in oesophageal squamous cell cancer. Nature 509, 91-95. https://doi.org/10.1038/ nature13176 (2014).

12. Hao, J. J. et al. Spatial intratumoral heterogeneity and temporal clonal evolution in esophageal squamous cell carcinoma. Nat. Genet. 48, 1500-1507. https://doi.org/10.1038/ng.3683 (2016).

13. Hu, N. et al. Genomic landscape of somatic alterations in esophageal squamous cell carcinoma and gastric cancer. Cancer Res. 76, 1714-1723. https://doi.org/10.1158/0008-5472.CAN-15-0338 (2016).

14. Nagtegaal, I. D. et al. The 2019 WHO classification of tumours of the digestive system. Histopathology 76, 182-188. https://doi. org/10.1111/his.13975 (2020).

15. Cormier, K. W. \& Woodgett, J. R. Recent advances in understanding the cellular roles of GSK-3. F1000 Res. https://doi.org/10.12688 /f1000research.10557.1 (2017).

16. Patel, P. \& Woodgett, J. R. Glycogen synthase kinase 3: a kinase for all pathways?. Curr. Top. Dev. Biol. 123, 277-302. https://doi. org/10.1016/bs.ctdb.2016.11.011 (2017).

17. Beurel, E., Grieco, S. F. \& Jope, R. S. Glycogen synthase kinase-3 (GSK3): regulation, actions, and diseases. Pharmacol. Ther. 148, 114-131. https://doi.org/10.1016/j.pharmthera.2014.11.016 (2015).

18. McCubrey, J. A. et al. Diverse roles of GSK-3: tumor promoter-tumor suppressor, target in cancer therapy. Adv. Biol. Regul. 54, 176-196. https://doi.org/10.1016/j.jbior.2013.09.013 (2014).

19. Miyashita, K. et al. An emerging strategy for cancer treatment targeting aberrant glycogen synthase kinase $3 \beta$. Anticancer Agents Med. Chem. 9, 1114-1122. https://doi.org/10.2174/187152009789734982 (2009).

20. Domoto, T. et al. Glycogen synthase kinase-3 $\beta$ is a pivotal mediator of cancer invasion and resistance to therapy. Cancer Sci. 107, 1363-1372. https://doi.org/10.1111/cas.13028 (2016).

21. Walz, A. et al. Molecular pathways: revisiting glycogen synthase kinase- $3 \beta$ as a target for the treatment of cancer. Clin. Cancer Res. 23, 1891-1897. https://doi.org/10.1158/1078-0432.CCR-15-2240 (2017).

22. Nagini, S., Sophia, J. \& Mishra, R. Glycogen synthase kinases: moonlighting proteins with theranostic potential in cancer. Sem. Cancer Biol. 56, 25-36. https://doi.org/10.1016/j.semcancer.2017.12.010 (2019).

23. Domoto, T., Uehara, M., Bolidong, D. \& Minamoto, T. Glycogen synthase kinase $3 \beta$ in cancer biology and treatment. Cells 9, E1388. https://doi.org/10.3390/cells9061388 (2020).

24. Aristizabal Prada, E. T. et al. GSK3a/ß: a novel therapeutic target for neuroendocrine tumors. Neuroendocrinology 106, 335-351. https://doi.org/10.1159/000481887 (2018).

25. Aristizabal Prada, E. T. et al. The role of GSK3 and its reversal with GSK3 antagonism in everolimus resistance. Endocr. Relat. Cancer 25, 893-908. https://doi.org/10.1530/ERC-18-0159 (2018).

26. Miyanaga, S. et al. Concentration-dependent radiosensitizing effect of docetaxel in esophageal squamous cell carcinoma cells. Int. J. Oncol. 48, 517-524. https://doi.org/10.3892/ijo.2015.3291 (2016).

27. Okumura, T., Shimada, Y., Imamura, M. \& Yasumoto, S. Neurotrophin receptor p75(NTR) characterizes human esophageal keratinocyte stem cells in vitro. Oncogene 22, 4017-4026. https://doi.org/10.1038/sj.onc.1206525 (2003).

28. Brierley, J., Gospodarowicz, M. K. \& Wittekind, C. TNM Classification of Malignant Tumours 8th edn, 68-70 (Wiley, Hoboken, 2017).

29. Mai, W. et al. Deregulated GSK3 $\beta$ sustains gastrointestinal cancer cells survival by modulating human telomerase reverse transcriptase and telomerase. Clin. Cancer Res. 15, 6810-6819. https://doi.org/10.1158/1078-0432.CCR-09-0973 (2009).

30. Bhat, R. et al. Structural insights and biological effects of glycogen synthase kinase 3-specific inhibitor AR-A014418. J. Biol. Chem. 278, 45937-45945. https://doi.org/10.1074/jbc.M306268200 (2003).

31. Coghlan, M. P. et al. Selective small molecule inhibitors of glycogen synthase kinase-3 modulate glycogen metabolism and gene transcription. Chem. Biol. 7, 793-803. https://doi.org/10.1016/s1074-5521(00)00025-9 (2000).

32. Pyko, I. V. et al. Glycogen synthase kinase $3 \beta$ inhibition sensitizes human glioblastoma cells to temozolomide by affecting $\mathrm{O}^{6}$-methylguanine DNA methyltransferase promoter methylation via c-Myc signaling. Carcinogenesis 34, 2206-2217. https:// doi.org/10.1093/carcin/bgt182 (2013).

33. Chandrashekar, D. S. et al. UALCAN: a portal for facilitating tumor subgroup gene expression and survival analyses. Neoplasia 19, 649-658. https://doi.org/10.1016/j.neo.2017.05.002 (2017).

34. Zamek-Gliszczynski, M. J. et al. Pharmacokinetics, metabolism, and excretion of the glycogen synthase kinase- 3 inhibitor LY2090314 in rats, dogs, and humans: a case study in rapid clearance by extensive metabolism with low circulating metabolite exposure. Drug Metab. Disp. 41, 714-726. https://doi.org/10.1124/dmd.112.048488 (2013).

35. Miyashita, K. et al. Potential therapeutic effect of glycogen synthase kinase $3 \beta$ inhibition against human glioblastoma. Clin. Cancer Res. 15, 887-897. https://doi.org/10.1158/1078-0432.CCR-08-0760 (2009).

36. Dewi, F. R. P. et al. Colorectal cancer cells require glycogen synthase kinase-3 3 for sustaining mitosis via translocated promoter region (TPR)-dynein interaction. Oncotarget 9, 13337-13352. https://doi.org/10.18632/oncotarget.24344 (2018).

37. Ministry of Education, Culture, Sports, Science and Technology. Fundamental Guidelines for Proper Conduct of Animal Experiment and Related Activities in Academic Research Institutions, https://www.lifescience.mext.go.jp/policies/pdf/an_material011.pdf (2006). 
38. Otto, T. \& Sicinski, P. Cell cycle proteins as promising targets in cancer therapy. Nat. Rev. Cancer. 17, 93-115. https://doi. org/10.1038/nrc.2016.138 (2017).

39. Gray, J. E. et al. A first-in-human phase I dose-escalation, pharmacokinetic, and pharmacodynamic evaluation of intravenous LY2090314, a glycogen synthase kinase 3 inhibitor, administered in combination with pemetrexed and carboplatin. Invest. New Drugs. 33, 1187-1196. https://doi.org/10.1007/s10637-015-0278-7 (2015).

40. Rizzieri, D. A. et al. An open-label phase 2 study of glycogen synthase kinase-3 inhibitor LY2090314 in patients with acute leukemia. Leuk. Lymphoma 57, 1800-1806. https://doi.org/10.3109/10428194.2015.1122781 (2016).

41. Atkinson, J. M. et al. Activating the Wnt/ß-catenin pathway for the treatment of melanoma-application of LY2090314, a novel selective inhibitor of glycogen synthase kinase-3. PLOS ONE 10, e0125028. https://doi.org/10.1371/journal.pone.0125028 (2015).

42. Petty, R. D. et al. Gefitinib and EGFR gene copy number aberrations in esophageal cancer. J. Clin. Oncol. 35, 2279-2287. https:// doi.org/10.1200/JCO.2016.70.3934 (2017).

43. Doi, T. et al. Safety and antitumor activity of the anti-programmed death-1 antibody pembrolizumab in patients with advanced esophageal carcinoma. J. Clin. Oncol. 36, 61-67. https://doi.org/10.1200/JCO.2017.74.9846 (2018).

44. Ferlay, J. et al. Cancer incidence and mortality worldwide: sources, methods and major patterns in GLOBOCAN 2012. Int. J. Cancer 136, E359-386. https://doi.org/10.1002/ijc.29210 (2015).

45. Paccez, J. D. et al. Inactivation of GSK3 $\beta$ and activation of NF- $\kappa B$ pathway via Axl represents an important mediator of tumorigenesis in esophageal squamous cell carcinoma. Mol. Biol. Cell 26, 821-831. https://doi.org/10.1091/mbc.E14-04-0868 (2015).

46. Wang, J. S. et al. Lithium inhibits proliferation of human esophageal cancer cell line Eca-109 by inducing a G2/M cell cycle arrest. World J. Gastroenterol. 14, 3982-3989. https://doi.org/10.3748/wjg.14.3982 (2008).

47. Gao, S. et al. Inhibition of glycogen synthase kinase 3 beta (GSK3 $\beta$ ) suppresses the progression of esophageal squamous cell carcinoma by modifying STAT3 activity. Mol. Carcinog. 56, 2301-2316. https://doi.org/10.1002/mc.22685 (2017).

48. Malumbres, M. et al. Cyclin-dependent kinases: a family portrait. Nat. Cell Biol. 11, 1275-1276. https://doi.org/10.1038/ncb11 09-1275 (2009).

49. Yoshino, Y. \& Ishioka, C. Inhibition of glycogen synthase kinase-3 beta induces apoptosis and mitotic catastrophe by disrupting centrosome regulation in cancer cells. Sci. Rep. 5, 13249. https://doi.org/10.1038/srep13249 (2015).

50. Schiller, W. Early diagnosis of carcinoma of the cervix. Surg. Gynecol. Obstet. 56, 210-222 (1933).

51. Ferreira, L. M., Hebrant, A. \& Dumont, J. E. Metabolic reprogramming of the tumor. Oncogene 31, 3999-4011. https://doi. org/10.1038/onc.2011.576 (2012).

52. Cantor, J. R. \& Sabatini, D. M. Cancer cell metabolism: one hallmark, many faces. Cancer Discov. 2, 881-898. https://doi. org/10.1158/2159-8290.CD-12-0345 (2012).

53. Lu, J. The Warburg metabolism fuels tumor metastasis. Cancer Metastasis Rev. 38, 157-164. https://doi.org/10.1007/s10555-01909794-5 (2019).

54. Hochwald, J. S. \& Zhang, J. Glucose oncometabolism of esophageal cancer. Anticancer Agents Med. Chem. 17, 385-394. https:// doi.org/10.2174/1871520616666160627092716 (2017).

55. Hay, N. Reprogramming glucose metabolism in cancer: can it be exploited for cancer therapy?. Nat. Rev. Cancer 16, 635-649. https ://doi.org/10.1038/nrc.2016.77 (2016).

\section{Acknowledgements}

We acknowledge Dr. Ilya V. Pyko in our lab for assistance with animal experiments and Dr. Barry Iacopetta (University of Western Australia) for critical review and editing of the manuscript. This study was supported by Grants-in-Aid for Scientific Research from the Ministry of Education, Science, Sports, Technology and Culture and from the Japan Society for the Promotion of Science (T. Minamoto).

\section{Author contributions}

T.D. and T.M. made conception and design. D.B. and T.D. provided the development of methodology. D.B., T.D. and M.U. got the acquisition of data. D.B., T.D., M.U. and H.S. analyzed and interpreted the data. D.B., T.D. and T.M. wrote and reviewed the manuscript. T.O., Y.E., M.N., I.N., T.M. and R.W.W. provided the administrative, technical or material support. All authors critically revised the article. All authors reviewed final version of the manuscript and approved it for submission. T.M. supervised the study.

\section{Competing interests}

The authors declare no competing interests.

\section{Additional information}

Supplementary information is available for this paper at https://doi.org/10.1038/s41598-020-68713-9.

Correspondence and requests for materials should be addressed to T.M.

Reprints and permissions information is available at www.nature.com/reprints.

Publisher's note Springer Nature remains neutral with regard to jurisdictional claims in published maps and institutional affiliations.

Open Access This article is licensed under a Creative Commons Attribution 4.0 International License, which permits use, sharing, adaptation, distribution and reproduction in any medium or format, as long as you give appropriate credit to the original author(s) and the source, provide a link to the Creative Commons license, and indicate if changes were made. The images or other third party material in this article are included in the article's Creative Commons license, unless indicated otherwise in a credit line to the material. If material is not included in the article's Creative Commons license and your intended use is not permitted by statutory regulation or exceeds the permitted use, you will need to obtain permission directly from the copyright holder. To view a copy of this license, visit http://creativecommons.org/licenses/by/4.0/.

(C) The Author(s) 2020 